\title{
2013 Canadian Association of Gastroenterology Educational Needs Assessment Report
}

\author{
Craig Render MD, VP CAG Education Affairs
}

\begin{abstract}
$\mathrm{T}$ he annual survey of Canadian Association of Gastroenterology (CAG) members' educational needs was conducted via an online survey during March and April. A total of 157 individuals completed the full survey. Similar to previous years, inflammatory bowel disease (IBD) topics were most in demand for future educational events. Other highly rated areas were: endoscopic techniques, celiac disease, non-IBD intestinal disorders, gastrointestinal infections and chronic diarrhea.
\end{abstract}

\section{INTRODUCTION}

The purpose of the CAG needs assessment was to provide guidance to the Executive and CAG Education Affairs on areas of greatest educational need. Conducting a needs assessment is a requirement for accreditation of educational events in accordance with the Royal College of Physicians and Surgeons of Canada.

\section{METHODS}

The members of Education Affairs 2013 include Drs Lana Bistritz, Nazira Chatur, Maria Cino, Jamie Gregor, Samir Grover, Phillip Hassard, Gilaad Kaplan, Adriana Lazarescu, Maitreyi Raman, Peter Rossos, Connie Switzer, Kevin Waschke, Geoff Williams, Clarence Wong, Winnie Wong, and trainee members Zain Kassam and Catharine Walsh. A subgroup of the committee designed the needs assessment survey, which was a modified version of that used in 2012.

The needs assessment was posted online and members were requested by e-mail to complete the simple 'tick box' survey. Data were compiled and analyzed at the CAG National Office.

The survey collected basic demographic information and examined interest in topics for educational events. Respondents were asked to rate their interest in 56 potential topics for educational events using a five-point scale of no interest-minor interest-neutral/not sure-some interest-very interested.

\section{RESULTS}

A personalized e-mail request sent to CAG members in early March drew 171 respondents, of which 158 completed the full survey. This represents $14 \%$ of the solicited membership.

\section{Demographics}

All respondents were CAG members. Sixty-eight per cent were male and regarding education, $71 \%$ held an MD or equivalent degree, $27 \%$ and $19 \%$ held a $\mathrm{PhD}$ or MSc, respectively, while $11 \%$ held another degree. Of the 123 respondents for whom the question was applicable the year of medical school graduation was before 1980 for $18 \%, 1980$ to 1989 for $20 \%, 1990$ to 1999 for $24 \%, 2000$ to 2004 for $21 \%$ and 2005 or later for $18 \%$. For the 132 respondents for whom the question was applicable, the majority were predominantly teaching-hospital based (70\%), rather than being community-based with $(29 \%)$ or without $(<1 \%)$ hospital privileges.

Most replies were from individuals in Ontario (37\%), followed by Alberta (26\%), Quebec (13\%), and British Columbia (7\%), with responses distributed roughly in proportion to provincial population.

Respondents' specialty was identified as adult gastroenterology by $49 \%$, pediatric gastroenterology by $8 \%$ and hepatology by $<1 \%$. Basic and clinical scientists made up $22 \%$ and $3 \%$, respectively, of respondents. Residents and fellows accounted for 7\%, and 'Other' roles for $10 \%$.

Regarding where respondents spend their time, $42 \%$ identified clinical practice as their primary focus and $27 \%$ noted basic research $(>50 \%$ research). Clinician-researchers $(\leq 50 \%$ research $)$ and clinician-teachers ( $\leq 50 \%$ teaching) formed the next biggest group at $10 \%$ each. Less commonly individuals were involved in clinical research $(>50 \%)(7 \%)$, administration (>50\%) $(2 \%)$, or 'other' duties $(2 \%)$.

\section{Educational topics}

The percentage of respondents who were 'Very interested' in each topic are shown in Figures 1 to 4 for the 56 educational topics surveyed. Consistent with past years, IBD topics remain extremely popular; in addition endoscopic techniques, celiac disease, non-IBD intestinal disorders, GI infections and chronic diarrhea were among the most desired educational areas (Figure 1). When examined according to various demographic splits (adult versus pediatric gastroenterologist, and basic scientists) the most desired topics ranked somewhat differently (Table 1).

\section{DISCUSSION}

Fourteen per cent of the solicited membership participated in the survey. An ongoing priority for Education Affairs is to develop innovative and easy assessment tools to encourage greater participation by members to accurately reflect their educational needs.

IBD remains the highest priority of respondents despite yearly Canadian Digestive Diseases Week (CDDW) sessions in this area since 2002. Apart from IBD, endoscopic techniques, celiac disease, non-IBD intestinal disorders, gastrointestinal infections and chronic diarrhea were popular. CAG Education Affairs is actively working to increase the quantity and quality of educational materials and programs that members can utilize as part of their ongoing maintenance of certification activities. These findings, along with evaluations of CDDW 2013 and identification of unrecognized educational needs, will form the basis of the 2014 CDDW program.

\section{The CAG is proud to acknowledge its Benefactor Corporate Sponsors:}

AbbVie Corporation
Olympus Canada Inc

Janssen Inc

Takeda Canada Inc 


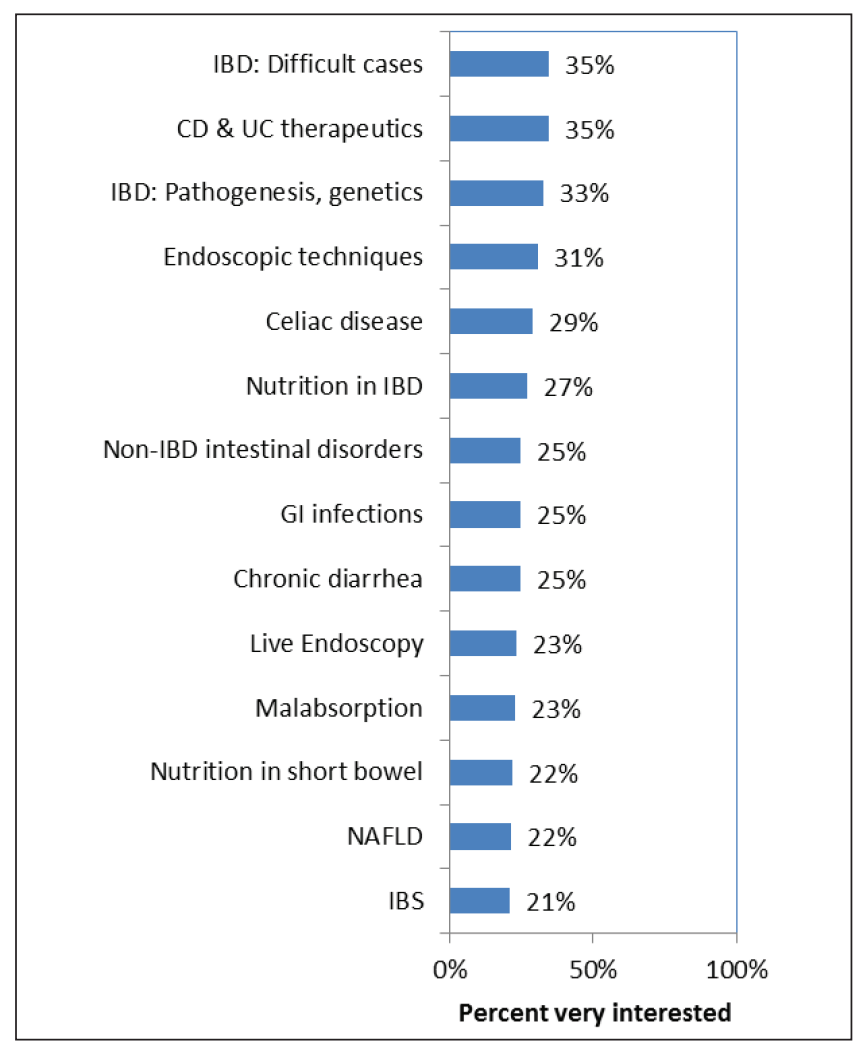

Figure 1) The 14 most popular topics for educational events based on the percent of respondents who were 'very interested' in the area. CD Crohn disease; GI Gastrointestinal; IBD Inflammatory bowel disease; IBS Irritable bowel syndrome; NAFLD Nonalcoholic fatty liver disease; UC Ulcerative colitis

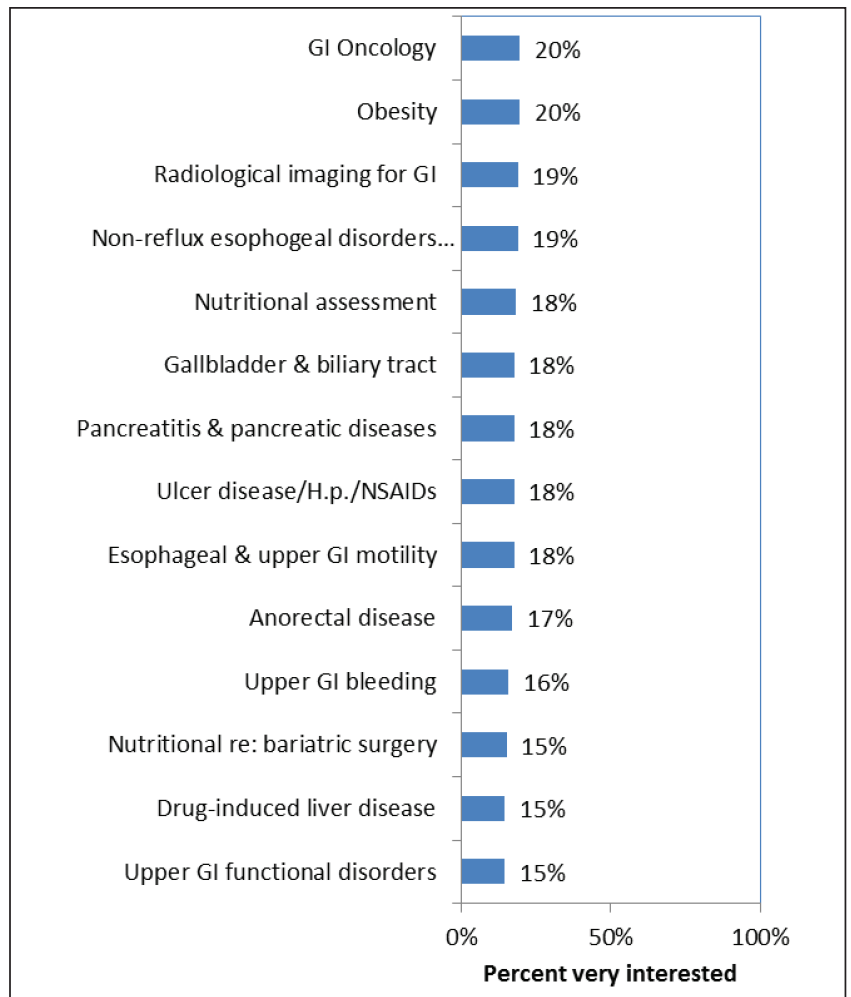

Figure 2) Educational topics in which $15 \%$ to $20 \%$ of respondents were 'very interested'. GI Gastrointestinal; H.p. Helicobacter pylori; NSAIDS Nonsteroidal anti-inflammatory drugs

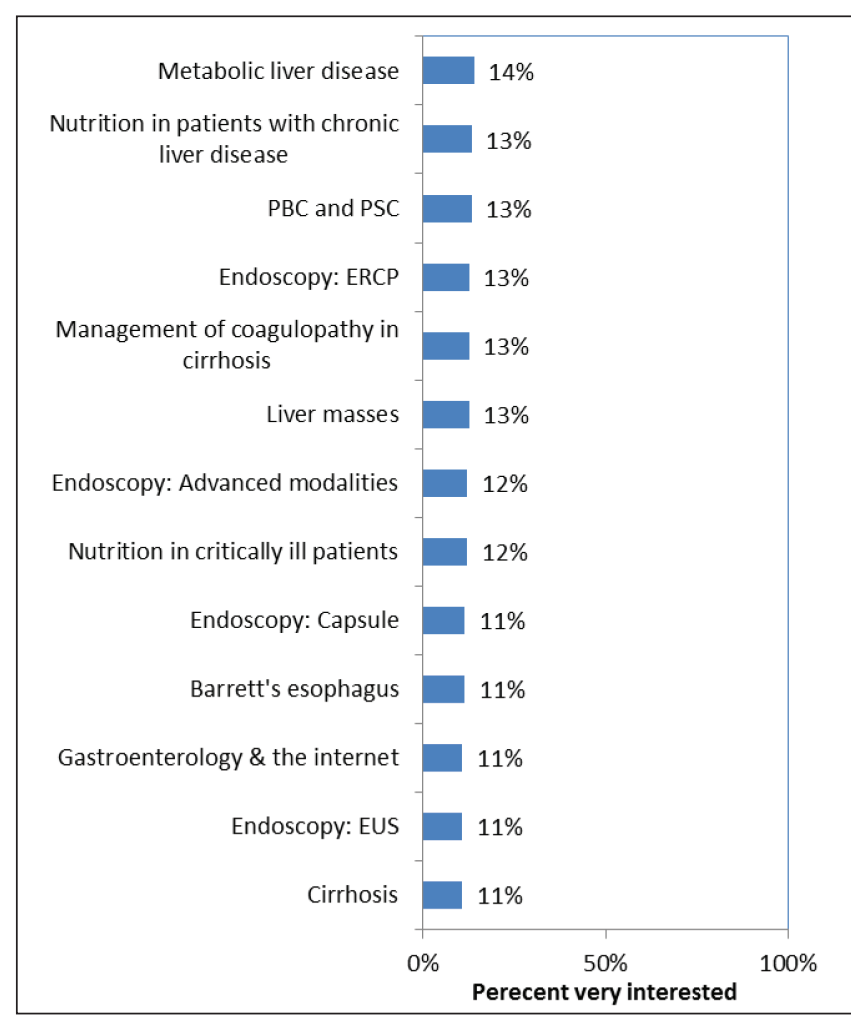

Figure 3) Educational topics in which $11 \%$ to $14 \%$ of respondents were 'very interested'. ERCP Endoscopic retrograde cholangiopancreotography; EUS Endoscopic ultrasound; PBC Primary biliary cirrhosis; PSC Primary sclerosing cholangitis

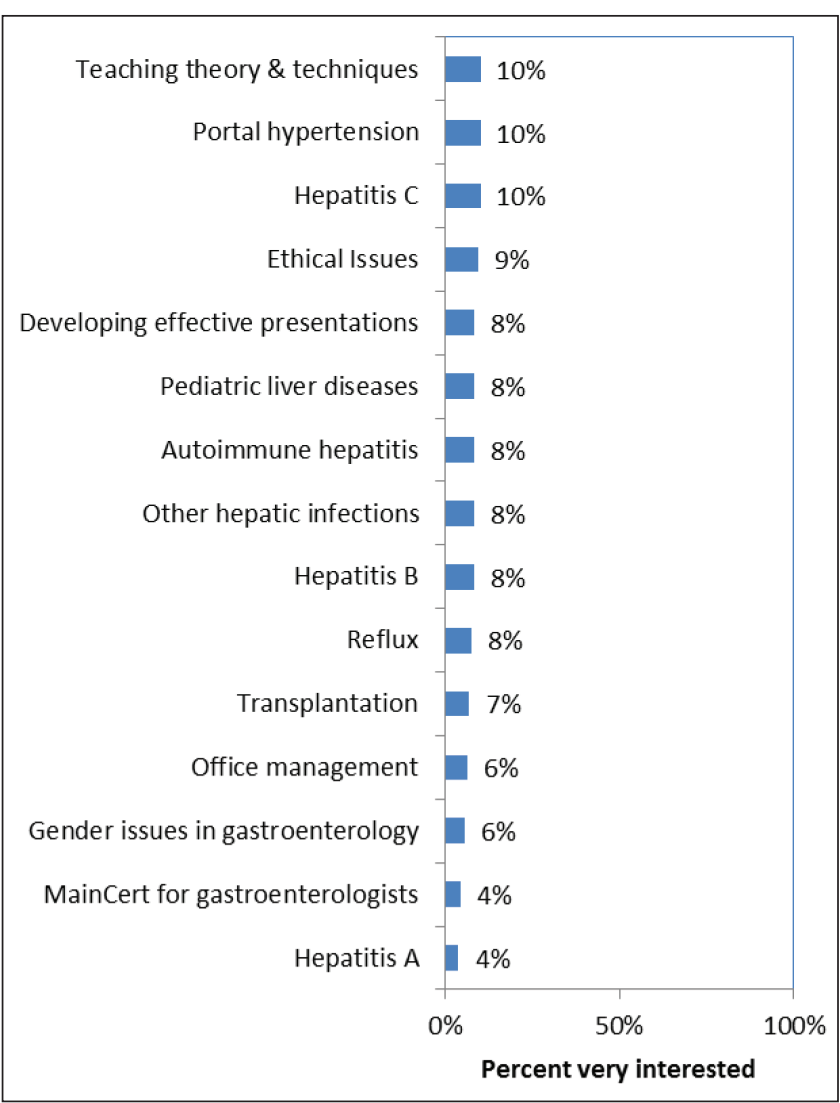

Figure 4) Educational topics in which $4 \%$ to $10 \%$ of respondents were 'very interested' 
TABLE 1

Most popular educational topics according to respondent subgroup

\begin{tabular}{|c|c|c|c|c|c|}
\hline & \multicolumn{5}{|c|}{ Choice, (\% very interested) } \\
\hline & 1 & 2 & 3 & 4 & 5 \\
\hline $\begin{array}{l}\text { Gastroenterologists - } \\
\text { Adult }(n=76)\end{array}$ & $\begin{array}{c}\text { Endoscopic techniques } \\
\text { and therapeutics } \\
(43.4 \%) \\
\end{array}$ & $\begin{array}{c}\text { IBD difficult cases } \\
(42.1 \%)\end{array}$ & Celiac disease (38.2\%) & $\begin{array}{c}\text { CD/UC therapeutics } \\
(36.8 \%)\end{array}$ & Chronic diarrhea (31.6\%) \\
\hline \begin{tabular}{|l} 
Gastroenterologists - \\
Pediatric $(n=13)$
\end{tabular} & \begin{tabular}{|c|} 
IBD pathogenesis, \\
genetics, etilology (53.8\%)
\end{tabular} & $\begin{array}{c}\text { Nonreflux esophageal } \\
\text { disorders (46.2\%) } \\
\text { Pediatric liver diseases } \\
(46.2 \%) \\
\text { CD/UC therapeutics } \\
(46.2 \%) \\
\end{array}$ & $\begin{array}{c}\text { Chronic diarrhea (38.5\%) } \\
\text { Nutrition in IBD (38.5\%) } \\
\text { Nutrition in short bowel } \\
\text { syndrome }(38.5 \%)\end{array}$ & \begin{tabular}{|c|} 
Upper GI bleeding (30.8\%) \\
Celiac disease (30.8\%) \\
Live endoscopy (30.8\%)
\end{tabular} & \\
\hline Basic scientists $(n=37)$ & \begin{tabular}{|c|} 
IBD pathogenesis, \\
genetics, etilology (56.8\%)
\end{tabular} & $\begin{array}{c}\text { Obesity (32.4\%) } \\
\text { GI infections (32.4\%) }\end{array}$ & $\begin{array}{l}\text { GI oncology }(27 \%) \\
\text { Non-IBD intestional } \\
\text { disorders }(27 \%)\end{array}$ & $\begin{array}{c}\text { Nutrition in IBD }(21.6 \%) \\
\text { IBS }(21.6 \%) \\
\text { CD/UC therapeutics } \\
(21.6 \%)\end{array}$ & \\
\hline
\end{tabular}

CD Crohn disease; GI Gastrointestinal; IBD Inflammatory bowel disease; IBS Irritable bowel syndrome; UC Ulcerative colitis 


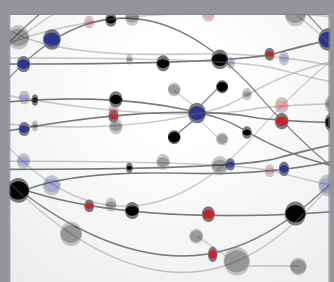

The Scientific World Journal
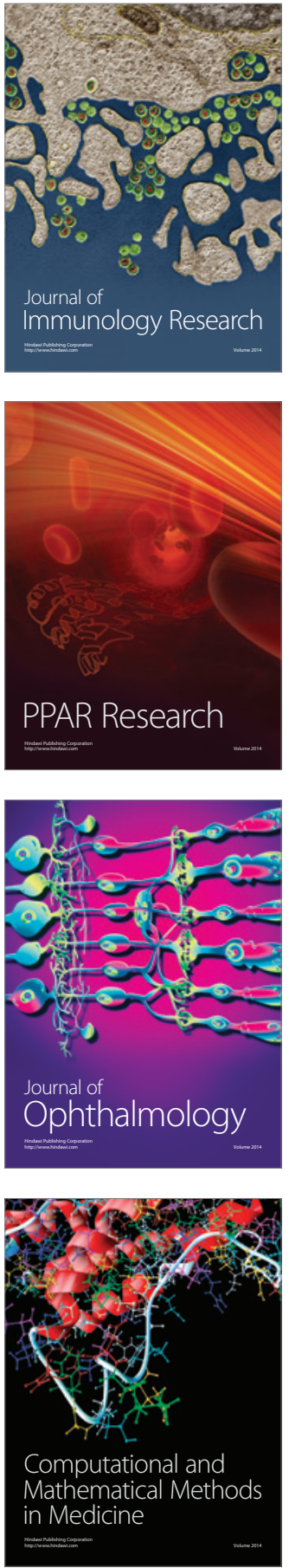

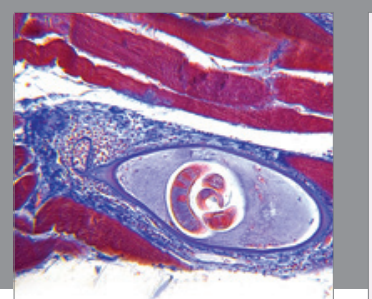

Gastroenterology Research and Practice

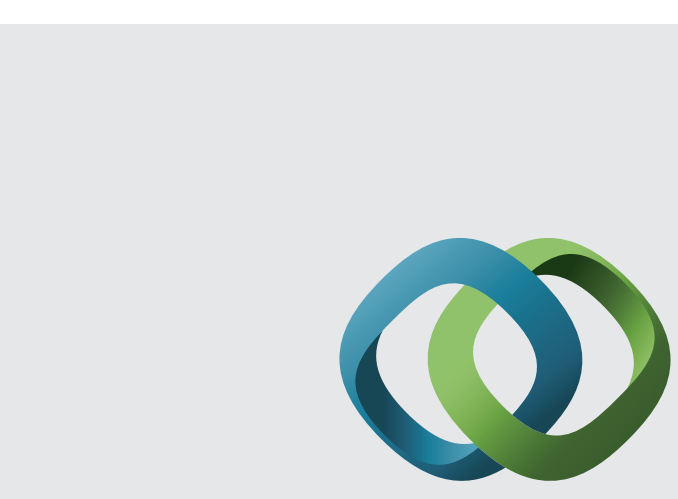

\section{Hindawi}

Submit your manuscripts at

http://www.hindawi.com
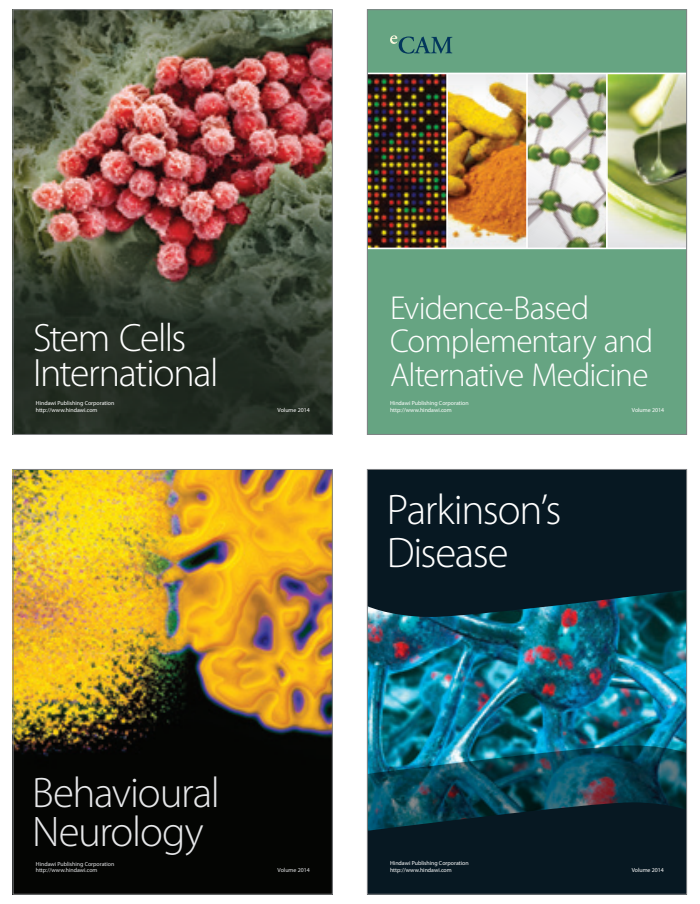
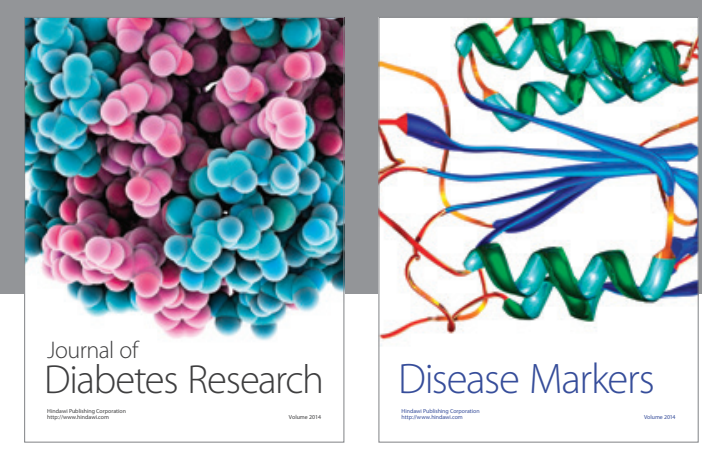

Disease Markers
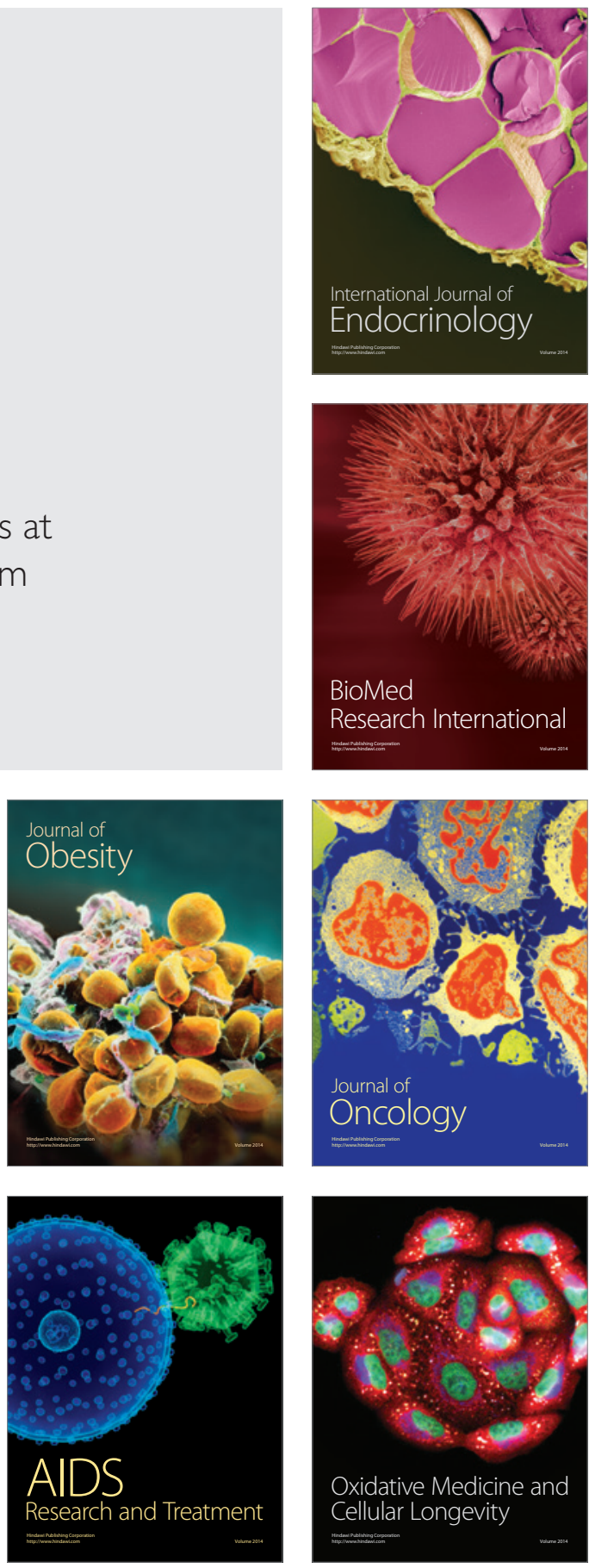